Bangladesh J. Sci. Res. 30(1\&2): 55-67, 2017 (December)

\title{
A STUDY ON DISASTER MANAGEMENT PRACTICES FOR VULNERABLE RURAL COMMUNITIES IN BANGLADESH
}

\author{
Bidyuth K. Mahalder, Md. Shahidul Islam ${ }^{1}$, B.M. Rabby Hossain ${ }^{1 *}$ and Farah Didul Nabi ${ }^{2}$
}

USAID Agricultural Extension Project, Dhaka, Bangladesh

\begin{abstract}
The current disaster knowledge and practices of disaster affected rural people in Bangladesh were investigated. Both qualitative and quantitative data were collected using structured questionnaire from 216 rural households. About $83 \%$ of the respondents perceived knowledge that brings about an increase in household income followed by learning new skills that contribute to reduction in disaster vulnerabilities $(75 \%)$ and knowledge that helps in the decision making process (67\%). A total of $91 \%$ of respondents, irrespective of literacy, are practicing tacit or oral knowledge sharing in their day to day lives. The sample respondents acquired disaster knowledge from different sources, including neighbors and relatives $(82 \%)$, social workers $(50 \%)$, mass media $(45 \%)$, religious institutions (38\%) and the village markets (32\%). For those that received their knowledge from the village market, the information is mainly gathered by the literate people $(37 \%)$ as opposed to those that are illiterate $(26 \%)$. In updating acquired knowledge, $76 \%$ respondents validated through self observations and $58 \%$ by consultation and communication with family members or neighbors. Interestingly, more than $74 \%$ respondents reported that an inadequate financial resource is an important barrier to gaining improved knowledge on disaster management in rural areas. About $69 \%$ of the respondents stated that the early warning messages provided by various agencies are 'very useful', whereas $23 \%$ believed them to be 'useful' and $8 \%$ as 'partially useful'. Posters, booklets and leaflets were identified as the most available and important disaster knowledge materials $(82 \%)$. The study results suggested that the establishment of the rural information and knowledge centre and an easily understandable forecasting system would be very useful to improve the disaster knowledge for the rural poor.
\end{abstract}

Key words: Disaster management, Vulnerable rural area, Communities

\section{Introduction}

Bangladesh is one of the most disaster prone countries in the world of about 144 million people within its 147,570 sq. km territory. Natural and human induced hazards such as floods, cyclones, droughts, tidal surges, tornadoes, earthquakes, river erosion, the arsenic contents of ground water, water logging, water salinity and various forms of pollution are the frequent occurrences Bangladesh faces on a regular basis (WB 2007).

Major disasters have had massive human and social impacts: official estimates are that 1,38,000 people were killed during the 1991 cyclone, whilst 31 million people were directly affected by the 1998 floods. The 2007 floods directly affected over 14 million people (WB 2007) and the cyclone Sidr of November 2007 affected 30 districts and about 9 million people (WB 2008).

*Author for correspondence: <hossain.dsm@du.ac.bd>. ${ }^{1}$ Department of Disaster Science and Management, University of Dhaka, Dhaka-1000, Bangladesh. ${ }^{2}$ Department of Geology, University of Dhaka, Dhaka-1000, Bangladesh. 
Knowledge is interpreted as a "sum of relationships of meanings that people create in their minds from available information, their experience, their feelings, and their ideas" (Beard 2003). Limited access to appropriate type of knowledge and resources of poor people is a critical concern in reducing knowledge poverty (Velden 2002). In the current disaster perspectives of Bangladesh, a huge amount of information disseminated by various agencies is not always capable of generating knowledge for the poor communities. Organizations mostly transfer more 'information' than 'real complete knowledge'. Efforts were made to make information available to the poor through various means such as technology, booklets and printed information and audio visual means but little has been achieved in reducing the knowledge poverty of rural poor communities (Practical Action 2007).

Conventional knowledge management practices of organizational experts, scientists and researchers have failed to empower poor people and are incapable of developing a knowledge-rich community of poor people. Therefore, the present study was conducted to observe the current status of knowledge management and practices for flood and cyclone affected vulnerable rural people, especially for the poor, who have limited access to advanced information and communication technology.

The present study attempted to investigate the people's perception of knowledge; types of knowledge used in their livelihoods, barriers to knowledge management and the right methods and approaches are required for improvement of knowledge and practices in reducing flood and cyclone vulnerabilities. The study also focused on observing the relationships of knowledge and practices with effectiveness of flood or cyclone early warning system and different knowledge materials for the targeted segments of the rural disadvantageous communities.

\section{Materials and Methods}

The present study was conducted in two cyclone prone coastal districts (Fig.1) affected by cyclone Sidr 2007 (i.e. Bagerhat and Barguna) and one northwest district affected by flood 2007 (i.e. Tangail) from June 2011 to July 2012.

The present study was designed based on literature review and extracts of local knowledge and information. Considering the strength and weakness of survey and Participatory Rural Appraisal (PRA) tools (Chamber 1994), the current study integrated the use of both qualitative and quantitative tools.

The following were the criteria for selection of the participants of most disaster vulnerable groups both in qualitative and quantitative assessment purposes:

Farmer: The person who cultivates his own land and does not work as day laborer, might have other sources of income.

Fisherman: The person who maintains his family mainly depending on catching fish or with small fish farming, might have agricultural land. 
Landless: The person who maintains his family through selling daily labor, or pulling rickshaw or van and does not have any productive agricultural land.

Woman: The woman, who supports her family through household activities and does not work as primary earner of the family.

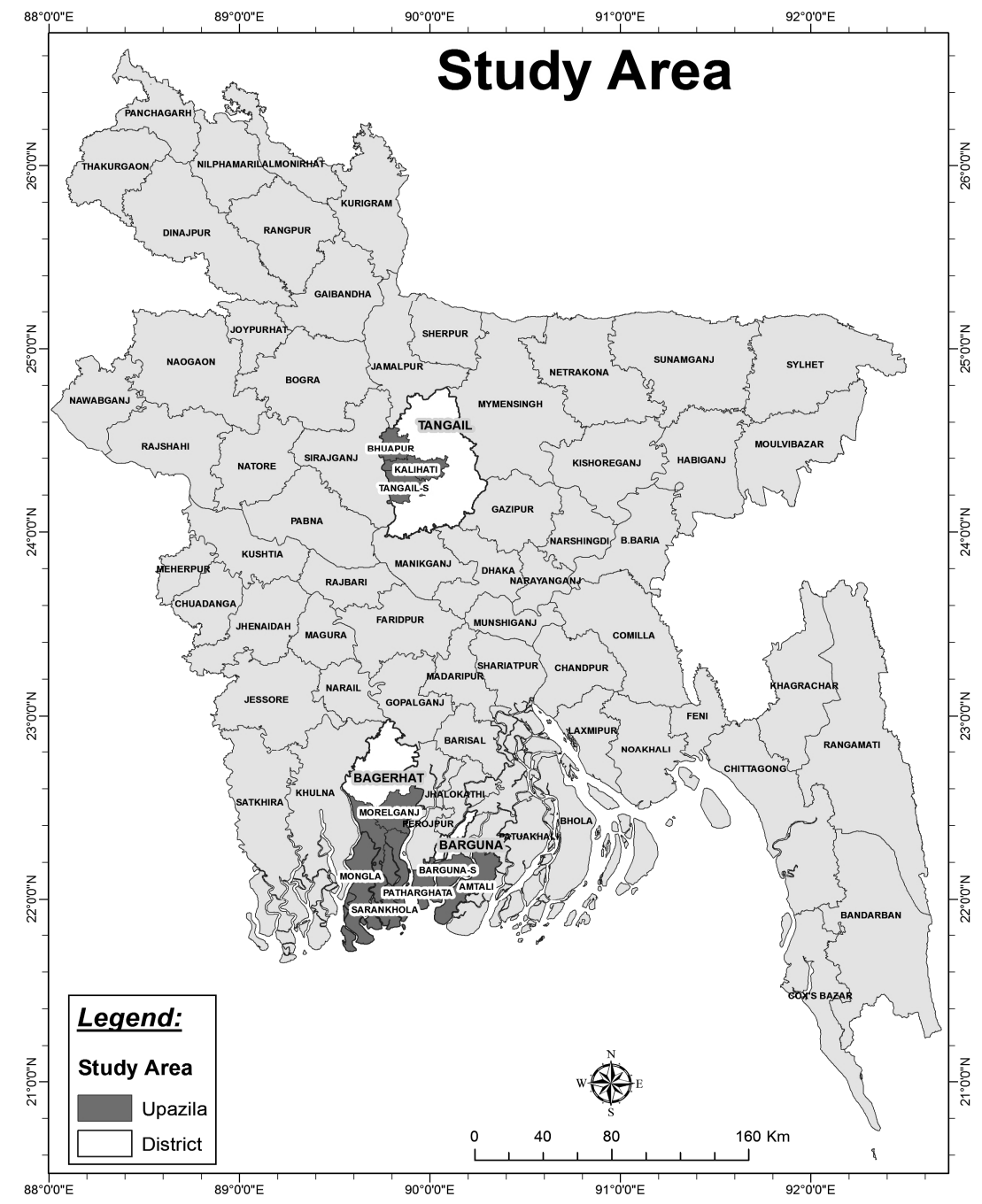

Fig.1. Map showing the locations of the study area.

The well-being analysis technique (Mahalder et al. 2009) was used as the quick and effective means of assessing socioeconomic status of the community people for identifying participants representing above mentioned four disaster vulnerable groups. The names of all households' heads in a community were listed by the key informants (individuals knowledgeable about community context, who were older and respected by other villagers). 
Five key informants were engaged to categorize all the households (on average 30 to 45) of a selected community according to the predetermined five wealth ranking indicators i.e. occupation, land ownership, education, types of housing and family savings. In this way, a total 310 of households' socioeconomic information was collected by them. Three participants were selected from each disaster vulnerable group from the primarily produced list of 30 to 45 households in each community. It was also considered that $50 \%$ of the participants were literate (at least can read and write) and remaining 50\% were illiterate (cannot read and write). In this way, a total of 12 participants from one community and 108 participants from 9 communities were selected for the study purposes.

In each community, 12 selected participants participated in the Focus Group Discussions (FGD). A total of 108 people participated in 9 FGD sessions in 9 communities. The quantitative information was collected through a household survey interviewing 108 participants attending in the FGD exercises. The compiled results obtained through FGD exercises were later compared with the household survey results.

Secondary data on population, households etc. of the study area were made available from published documents including population census reports of the Bangladesh Bureau of Statistics (BBS 2001).

\section{Results and Discussion}

\section{Demographic information of the respondents}

Age distribution: The survey of 108 households in 9 Upazilas under three districts revealed that about $94.3 \%$ of families were headed by males while the remaining $5.7 \%$ were headed by females. About $11.1 \%$ of respondents were over 50 years of age and $11.1 \%$ remained below 31 years. More than $78 \%$ of the respondents were from 31 to 50 years of age. The variation of age group distribution among the surveyed respondents was insignificant between flood and cyclone prone areas.

Primary occupations: Households depended on multi sources of income for their livelihoods along with the main sources like agriculture, fish farming, wage labour, domestic households' activities and rickshaw pulling. The respondents of the households' surveyed were primarily segmented into four marginalized disaster vulnerable groups through the key informants' information. So, the respondents occupation was less diversified.

Fig. 2 shows that primary occupation of $16.7 \%$ of the respondents were agricultural cropping, followed by fish farming (13.9\%), fisherman (13\%) and housewives (13\%). About $12 \%$ of the respondents were day labourers and $8.3 \%$ were van/rickshaw pullers. Only $6.5 \%$ of the households had agriculture cum fish farming in coastal region, i.e. in Bagerhat and Barguna.

Literacy: In the present study a person was defined as literate if he/she can read and write and understand a newspaper written in Bangla language. In this context $43.5 \%$ of the respondents were classified as illiterate, who did not receive any formal or informal education and cannot read and write any simple text. About $28.7 \%$ have completed only primary education (Class 1 to 5 ). 
This is worth to mention that the respondents categorized under primary education at least can read and understand the simple text written in Bangla language. It was also observed that about $25 \%$ of the participants were educated in secondary level (Class 6 to 10). Only $2.8 \%$ were found educated in higher secondary and graduate level (>class 10). In the following sections, the analysed results of literacy focused the relationships with knowledge perception, types, sources, barriers and improvement regarding disaster vulnerabilities.

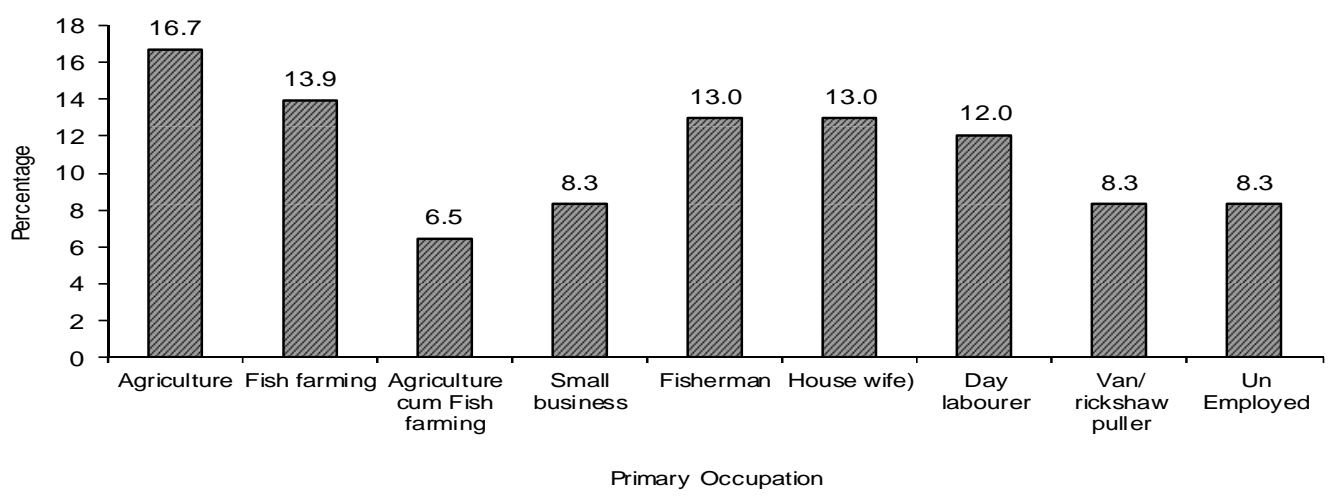

Fig. 2. Primary occupation of the respondents.

Perception of knowledge: The household survey results on knowledge perception (Table 1) illustrated that more than $83 \%$ of the respondents perceived knowledge with household income or better earnings followed by learning new skills on disaster management (75\%) and helps in better decision making (66.7\%).

Only $26 \%$ of the respondents perceived knowledge for increasing social prestige and interactions. Within the disaster vulnerable groups the fisherman and woman are highly ranked perceived knowledge as household income and better earnings. The household income and new skills were equally graded by landless group $(81.5 \%)$ whereas farmers prioritized the perceived knowledge as new skills and better decision making (77.8\%).

Table 1. Perception of knowledge by disaster vulnerable groups $(n=108)$.

\begin{tabular}{lccccc}
\hline $\begin{array}{l}\text { Perception of } \\
\text { knowledge }\end{array}$ & $\begin{array}{c}\text { Farmer } \\
(\%)\end{array}$ & $\begin{array}{c}\text { Landless } \\
(\%)\end{array}$ & $\begin{array}{c}\text { Fisherman } \\
(\%)\end{array}$ & $\begin{array}{c}\text { Woman } \\
(\%)\end{array}$ & $\begin{array}{c}\text { Total } \\
(\%)\end{array}$ \\
\hline Brings income for family & 74.1 & 81.5 & 92.6 & 85.2 & 83.3 \\
New skills on disaster mgt. & 77.8 & 81.5 & 74.1 & 66.7 & 75.0 \\
Helps in better decision making & 77.8 & 70.4 & 55.6 & 63.0 & 66.7 \\
Increase honour and respect & 40.7 & 48.1 & 48.1 & 33.3 & 42.6 \\
Increase social interactions & 22.2 & 44.4 & 18.5 & 18.5 & 25.9 \\
\hline
\end{tabular}


Similarly, the FGD exercise results showed that knowledge is an asset associated with the ability to engage people in diverse work, ways of earning and managing a family living with disadvantaged economical situation and disaster vulnerabilities. The FGD results also showed that women perceived knowledge as a tool to develop their families while men focused on the ability to utilize knowledge as a tool to develop technical expertise in their livelihoods, disaster preparedness and other occupational works.

Types of knowledge use: The study results illustrated that illiterate people prioritized tacit or oral knowledge for households' income and better earnings (75.0\%) followed by primary health care $(63.3 \%)$ and flood/cyclone or other disaster vulnerabilities $(62.5 \%)$. The household survey results also stated that reliance on tacit knowledge was higher amongst the illiterate than literate people due to inability to reading and writing (Table 2).

Both literate and illiterate respondents expressed their highest priority in tacit/oral knowledge for their livelihoods purposes and management of disaster vulnerabilities. The literate respondents had given almost equal priority of tacit $(52.4 \%)$ and explicit $(47.6 \%)$ knowledge in managing flood / cyclone or other disaster vulnerabilities.

Table 2. Types of knowledge use for different purposes $(n=108)$.

\begin{tabular}{llcc}
\hline \multirow{2}{*}{$\begin{array}{l}\text { Purpose of use } \\
\text { of knowledge }\end{array}$} & $\begin{array}{c}\text { Respondent } \\
\text { types }\end{array}$ & \multicolumn{2}{c}{ Use of knowledge types (\%) } \\
\cline { 3 - 4 } Household income and & Literate & 71.2 & Explicit/written \\
better earnings & Illiterate & 75.0 & 28.8 \\
Primary health & Literate & 59.6 & 25.0 \\
care & Illiterate & 63.3 & 40.4 \\
Management of flood/cyclone & Literate & 52.4 & 36.7 \\
or other disaster vulnerabilities & Illiterate & 62.5 & 47.6 \\
\hline
\end{tabular}

The most of the male participants of FGD expressed that explicit and tacit knowledge is equally important to them but females found tacit knowledge is more important regarding household management. Some of them felt that explicit knowledge was more important for their children than themselves as they had less or no formal education. The participants also mentioned that they can only apply about 25 to $30 \%$ of their explicit knowledge in their day to day life while their livelihoods were mostly dominated by the application of tacit knowledge.

Knowledge capturing, updating and sharing: The study attempted to examine the most dominant source of capturing knowledge regarding flood and cyclone preparedness, vulnerability and management. The analysed results showed that neighbors and relatives were the most dominant source $(81.5 \%)$ followed by non-government organization (NGO)/government organization $(\mathrm{GO}) /$ social organizations $(50 \%)$ and mass media $(45.4 \%)$. The survey results also revealed that only $31.5 \%$ of the respondents captured disaster related knowledge from village market (Table 3). 
The analysed results also showed that more percentage of literate people (37.0\%) captured disaster management related knowledge from the village market than illiterate people (25.9\%). The more percentage of literate people (53\%) was found dependent on media to get knowledge regarding disaster management than illiterate people (37\%). NGOs or government organizations were found to play a better role for disseminating flood related knowledge $(52.8 \%)$ rather than cyclone related knowledge (48.6\%).

Table 3. Sources of capturing knowledge by disaster types and literacy $(n=108)$.

\begin{tabular}{lccccc}
\hline \multirow{2}{*}{$\begin{array}{l}\text { Knowledge capturing } \\
\text { sources }\end{array}$} & \multicolumn{2}{c}{ Disaster type $(\%)$} & \multicolumn{2}{c}{ Literacy $(\%)$} & \multirow{2}{*}{$\begin{array}{c}\text { Total } \\
(\%)\end{array}$} \\
\cline { 2 - 5 } & Cyclone & Flood & Illiterate & Literate & \\
\hline Village market and fair place & 27.8 & 38.9 & 25.9 & 37.0 & 31.5 \\
Mass media (Radio, TV, Newspaper) & 44.4 & 47.2 & 37.0 & 53.7 & 45.4 \\
Neighbors and relatives & 81.9 & 80.6 & 81.5 & 81.5 & 81.5 \\
Local leaders/teachers/learned persons & 36.1 & 33.3 & 29.6 & 40.7 & 35.2 \\
NGO/GO/social workers at community & 48.6 & 52.8 & 44.4 & 55.6 & 50.0 \\
Academic/religious institutions & 31.9 & 50.0 & 35.2 & 40.7 & 38.0 \\
Other (Mobile, visit, outsiders etc.) & 13.9 & 36.1 & 18.5 & 24.1 & 21.3 \\
\hline
\end{tabular}

Fig. 3 shows that neighbors and relatives were the most dominant source of capturing knowledge regarding flood and cyclone for all classified social categories of people. Mobile, exposure visits and getting knowledge from outsiders were identified as the least important source.

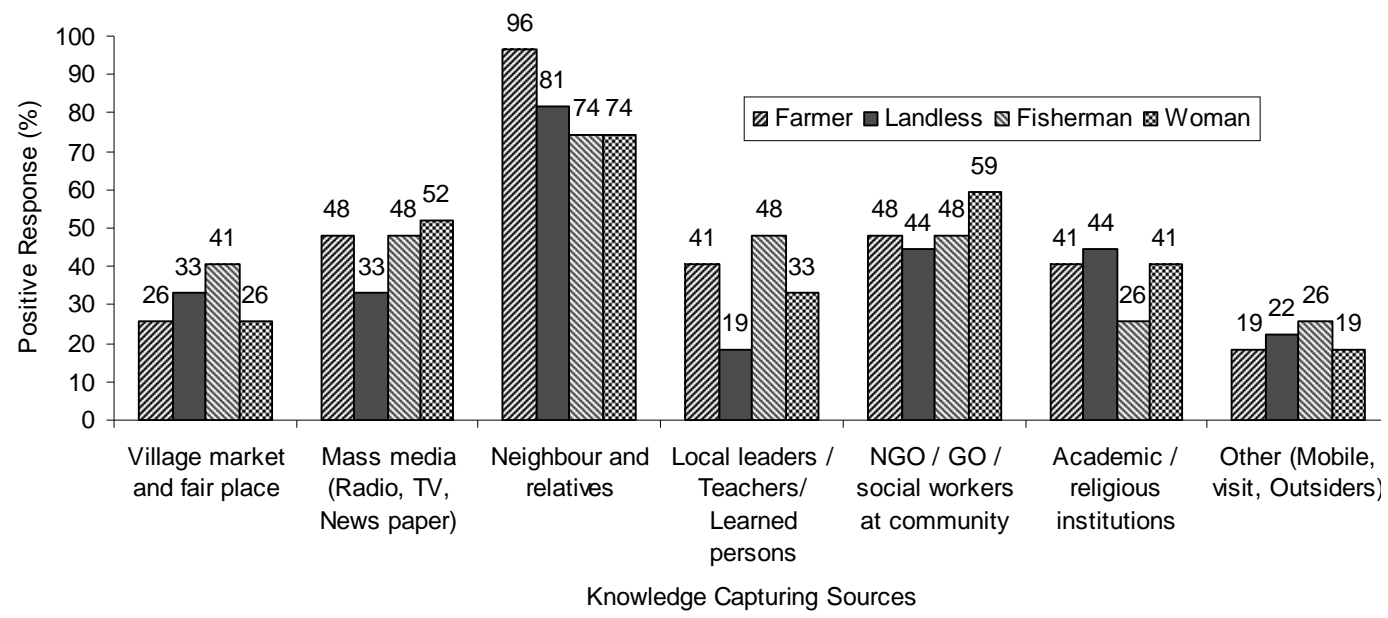

Fig. 3. Sources of capturing knowledge by disaster vulnerable groups $(n=108)$.

Among all categories, the women were identified as highest recipient of disaster related knowledge from $\mathrm{NGO} / \mathrm{GO} /$ social organizations as they were mostly involved with socio-economic 
services of NGOs. The village market and four place were also found to be the moderate source of knowledge regarding flood/cyclone management for all categories of respondents.

From above mentioned categories (Fig. 3), the higher percentage of farmers (96\%) followed by landless people $(81 \%)$ stated that neighbors and relatives played a very important role for disseminating knowledge regarding flood and cyclone management in the studied communities.

The FGD participants reported that the role of Government and NGOs were almost similar for capturing disaster management knowledge. The local representatives or community leaders were appeared to be a poor source of capturing knowledge regarding disaster management. The FGD participants also stated that they did not gather much diverse knowledge on flood / cyclone preparedness from market places where usually the male family members visit the place regularly.

The study observed that a majority of households ( $82 \%$ ) had a tendency to update their captured knowledge through various means and the remaining people (18\%) do not update it. Selfobservation and consultation process with family members were found to be the two most important means of updating knowledge for respondents' households.

The source of capturing knowledge may not always act as a good source of updating knowledge. For example, the role of media was found higher in capturing knowledge and information than updating. The updating mechanism found to be more self-driven than supported by organizations as NGO/GO campaigning media and visits were not appeared to be useful in updating knowledge.

The analysed results illustrated that almost equal percentage of literate (77.3\%) and illiterate (75\%) update their knowledge through self observation. The results also revealed that more number of illiterate people $(63.6 \%)$ update their knowledge through consultation process than literate (52.3\%) people (Fig. 4).

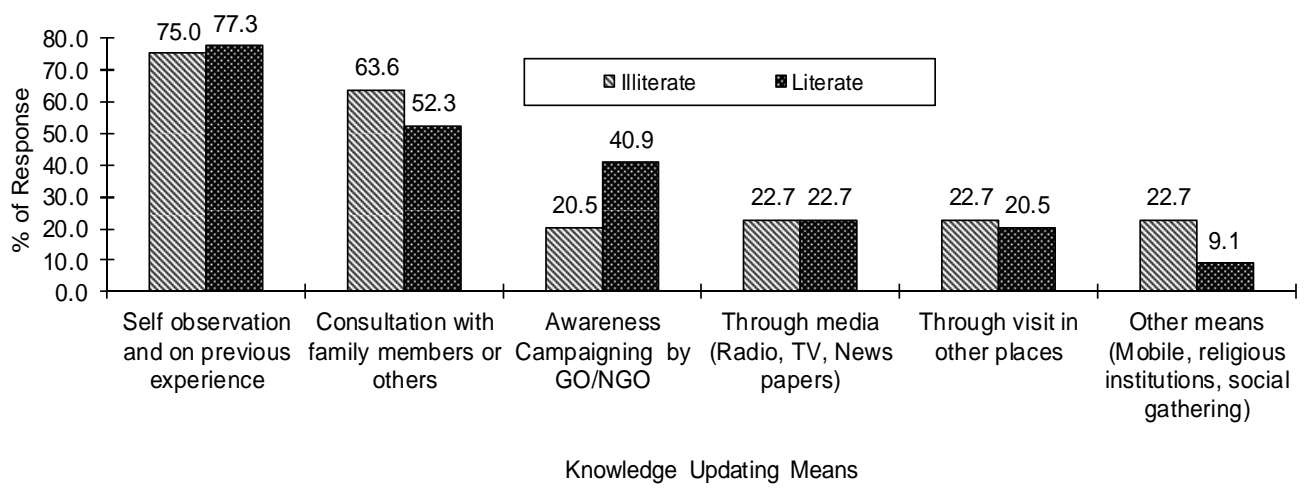

Fig. 4. Means of updating knowledge by literacy $(\mathrm{n}=88)$.

Almost double number of literate (40.9\%) than illiterate (20.5\%) respondents update their disaster vulnerabilities related knowledge through awareness creation activities of government and non-government organization. Religious institutions and mobile phone played important roles for illiterate $(22.7 \%)$ than literate $(9.1 \%)$ for updating their knowledge. 
The FGD exercise results showed that among all categories of respondents, the farmers were found highest dependent on self observation (80.8\%) than other categories. The higher numbers of women were found to be dependent of updating their knowledge through consultation process with family members $(60 \%)$. The higher percentage of landless and farmer categories of respondents were found to update their knowledge through visiting other places in comparison to other categories.

Once someone has access to new knowledge and it has been updated over a time, he/she starts to share it. Fig. 5 shows that households from vulnerable communities rarely shared knowledge with other communities and development organizations but with their family members (81.8\%), neighbors and their relatives $(86.4 \%)$.

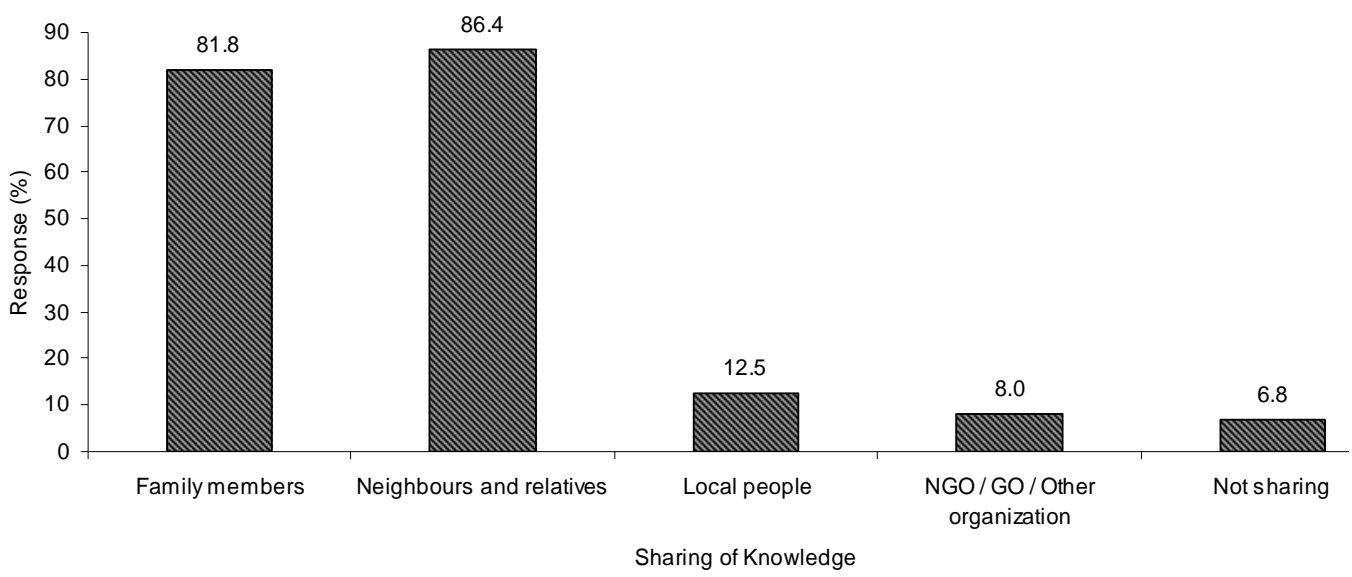

Fig. 5. Sharing of knowledge with others $(n=88)$.

Knowledge barriers and required measures to improve practices for preparedness: The survey results illustrated that the most important barrier to knowledge improvement in the studied communities was perceived by $73.9 \%$ of respondents to be the lack of resources such as money, electricity, radio and television. About $28.4 \%$ respondents expressed their opinion that lack of timeliness as the barrier of improvement of their knowledge. The household survey further stated that the lack of communicative language of media regarding knowledge on flood and cyclone was one of the important barriers to improvement of knowledge for $48.9 \%$ respondents. Lack of communication among communities (13.6\%) due to physical barriers, absence of promoting organization $(10.2 \%)$ and fragmentation of rural families $(4.5 \%)$ played the insignificant role as the barrier to improve knowledge. But less faith on present disaster forecasting system (35.2\%) found an important barrier to improve knowledge and disaster preparedness for the rural vulnerable communities (Table 4).

The results obtained through household survey revealed that establishment of rural information and knowledge centre (61.1\%) and easily understandable appropriate flood/cyclone 
forecasting system (12\%) were the most important driving forces to promote knowledge and practices regarding disaster management in rural communities. The literate households were likely to benefit more than the illiterate through rural knowledge sharing and the information centre. Publication of knowledge materials in local languages was also found to be an important means in promoting knowledge regarding cyclone and flood preparedness in reducing vulnerabilities (Table 5).

Table 4. Barriers to knowledge improvement by disaster vulnerable groups $(n=88)$.

\begin{tabular}{lccccc}
\hline \multirow{2}{*}{ Barriers for updating knowledge } & \multicolumn{3}{c}{ Disaster vulnerable group (\%) } & Total \\
\cline { 2 - 4 } & Farmer & Landless & Fisherman & Woman & $\%$ \\
\hline Lack of resources (e.g. money, electricity, & 80.8 & 68.2 & 80.0 & 65.0 & 73.9 \\
radio, television etc.) & 23.1 & 27.3 & 25.0 & 40.0 & 28.4 \\
Lack of timeliness & 38.5 & 40.9 & 25.0 & 35.0 & 35.2 \\
Less faith on appropriate forecasting system & 42.3 & 54.5 & 50.0 & 50.0 & 48.9 \\
Lack of communicative language of media & 3.8 & 18.2 & 10.0 & 25.0 & 13.6 \\
Lack of communication among community & 7.7 & 13.6 & 15.0 & 5.0 & 10.2 \\
Absence of promoting organization & 7.7 & 0.0 & 5.0 & 5.0 & 4.5 \\
Family fragmentation & & & & & \\
\hline
\end{tabular}

About $56 \%$ of the respondents stated that the internal and external linkage of the people i.e. if more people go outsides of their communities or outsiders visit their places could enhance the knowledge improvement process. A total of $13 \%$ respondents have expressed their views that easy media and information technology access for the rural poor will equip them with more knowledge about cyclone and flood management.

Table 5. Required supports to improve disaster knowledge and practices.

\begin{tabular}{|c|c|c|c|c|}
\hline \multirow{2}{*}{\multicolumn{2}{|c|}{$\begin{array}{l}\text { Intervention methods and types of support needed for } \\
\text { the communities }\end{array}$}} & \multicolumn{2}{|c|}{ Disaster type $(\%)$} & \multirow{3}{*}{$\begin{array}{c}\begin{array}{c}\text { Total } \\
(\%\end{array} \\
61.1\end{array}$} \\
\hline & & \multirow{2}{*}{$\begin{array}{c}\text { Cyclone } \\
62.5\end{array}$} & \multirow{2}{*}{$\begin{array}{l}\text { Flood } \\
58.3\end{array}$} & \\
\hline Appropriate & Establishment of rural information centre & & & \\
\hline intervention & Easily understandable appropriate forecasting system & 11.1 & 13.9 & 12.0 \\
\hline methods & Improvement of communication infrastructure & 9.7 & 5.6 & 8.3 \\
\hline \multirow{7}{*}{$\begin{array}{l}\text { Types of } \\
\text { supports } \\
\text { need }\end{array}$} & Through trained people at community level & 6.9 & 11.1 & 8.3 \\
\hline & Availability of learning materials at community level & 9.7 & 11.1 & 10.2 \\
\hline & Enhanced linkage of knowledge agents (internal / external) & 59.7 & 47.2 & 55.6 \\
\hline & Development of knowledge agents (e.g. volunteers) & 9.7 & 2.8 & 7.4 \\
\hline & Allocation of resources to test the new ideas / technology & 12.5 & 16.7 & 13.9 \\
\hline & Access of rural poor to media and information technology & 11.1 & 16.7 & 13.0 \\
\hline & Introducing disaster vulnerability knowledge to children & 6.9 & 16.7 & 10.2 \\
\hline
\end{tabular}


The FGD exercise results stated that the NGOs or other social development organizations can play an important role for further development and improvement of disaster related knowledge of the rural communities regarding disaster. A large number of FGD participants (60.2\%) expressed their views about obtaining support from government organizations in improving their knowledge on preparedness strategies for reducing vulnerabilities.

Effectiveness of early warning messages and knowledge materials: About $68.5 \%$ of the surveyed households stated that the early warning messages provided by various agencies was very useful, $23.1 \%$ mentioned as useful and $8.3 \%$ mentioned partially useful (Table 6). A large number of respondents found the early warning message effective for them; because they could prepare themselves getting information from various agencies. A total of $32.4 \%$ respondents reported that they could save their valuable assets by receiving early warning messages.

About $2 \%$ households could not save their valuable assets or did not find any safer place to move as they received delayed messages or lived far away from flood or cyclone shelters. More than $9 \%$ households reported that they did not get enough time to be prepared due to delayed early warning messages.

Table 6. Effectiveness of early warning messages $(n=108)$.

\begin{tabular}{|c|c|c|c|c|}
\hline \multirow{2}{*}{\multicolumn{2}{|c|}{$\begin{array}{l}\text { Effectiveness of early warning messages } \\
\text { and different reasons }\end{array}$}} & \multicolumn{2}{|c|}{ Disaster type (\%) } & \multirow{3}{*}{$\begin{array}{c}\text { Total } \\
\%\end{array}$} \\
\hline & & \multirow{2}{*}{$\begin{array}{c}\text { Cyclone } \\
68.1\end{array}$} & \multirow{2}{*}{$\begin{array}{l}\text { Flood } \\
69.4\end{array}$} & \\
\hline Effectiveness of & Very useful & & & \\
\hline $\begin{array}{l}\text { early warning } \\
\text { message }\end{array}$ & Useful & 25.0 & 19.4 & 23.1 \\
\hline & Partially useful & 6.9 & 11.1 & 8.3 \\
\hline \multirow{7}{*}{$\begin{array}{l}\text { Reasons for the } \\
\text { answers }\end{array}$} & Got time for preparedness & 20.8 & 27.8 & 23.1 \\
\hline & Could save the valuable belongings & 29.2 & 38.9 & 32.4 \\
\hline & Could move in safe places & 19.4 & 16.7 & 18.5 \\
\hline & Could save valuable assets and domestic animals & 19.4 & 5.6 & 14.8 \\
\hline & Did not get enough time for preparedness & 9.7 & 8.3 & 9.3 \\
\hline & Could not save valuable assets & 1.4 & 0.0 & 0.9 \\
\hline & No safer place to go & 0.0 & 2.8 & 0.9 \\
\hline
\end{tabular}

The study attempted to observe the availability of the information, education and communication (IEC) materials and its impact on studied communities for development of knowledge regarding disaster vulnerabilities. It was found that posters, booklets and leaflets were three of the most available and important knowledge materials within the reach of the respondents' households.

After analyzing the household survey results, it was observed that posters $(82.4 \%)$ were the most available knowledge material for community people. Folk song, audio and video were found popular only for $16 \%$ of the literate people. Booklets, leaflets and newsletters appeared less effective than posters, video and audio material. 
The FGD data suggested that audio cassette and folk song were relatively more important to the illiterate people for improving knowledge regarding disaster management along with livelihoods management. The FGD participants also reported that video is equally an effective knowledge material for both the literate and illiterate people. The participants also stated that posters are more effective to the literate people and audio is more effective with illiterate people.

\section{Conclusions}

The present study found that knowledge perception was relatively more influenced by literacy than social classified groups. Illiteracy was found to be strongly linked with higher dependency and application of tacit knowledge particularly among disadvantaged social groups. There is a big challenge to bring poor people in touch with appropriate knowledge capturing, updating and sharing that can empower the poor by enabling them to address their basic needs regarding disaster vulnerabilities and alleviate the poverty.

The single most important message from this study was to perceive knowledge not only as an organizational product and process but also as a human, social process that increases people's decision making power, generate interest of capturing new economic and cultural ideas, diverse skills, bring honor and helps to face the new challenges of their livelihoods. Attention on both tacit and explicit knowledge was found particularly important in a knowledge management system for the poor illiterate and socially, economically isolated groups/communities.

There needs to be a shift towards complete knowledge management which will press on diverging knowledge base, updating and sharing of both explicit and tacit knowledge (Wikipedia 2007). Current study indicates that rural poor and disaster vulnerable households mostly applied tacit knowledge in their daily lives due to their current literacy level and socio economic condition. Application of explicit knowledge is likely to increase with the development of literacy and socio economic status.

Knowledge sharing - an important part of the knowledge management culturally found to occur among family members, neighbors, friends and relatives in the studied areas can reach to a more meaningful outcome if organization/NGOs change their dominate role as a sender to both 'receiver' and 'sender'.

The results suggested that establishment of rural information and knowledge centre and easily understandable forecasting system would be the most important driving forces to improve knowledge and practices for flood and cyclone affected rural communities. In the remote areas including islands the warning dissemination and understanding of warnings need to be strengthened as a trigger for preparedness action and improvement of knowledge in reducing flood and cyclone vulnerabilities in Bangladesh. 


\section{References}

BBS. 2001. Bangladesh Population Census. 2001. Community series, zila: Bagerhat, Barguna and Tangail; Bangladesh Bureau of Statistics (BBS), Ministry of Planning, Government of Bangladesh, Dhaka, Bangladesh.

Beard, P. 2003. Introduction to knowledge management, fannie mae foundation; Papers of the summit on technology and community development. http://www. docstoc.com /docs/ 2705549/X-Introduction-toKnowledge-Management.

Chambers, R. 1994. The origins and practice of participatory rural appraisal; World development, 22(7): 953-969, http://prproject. blogsome.com.

Government of Bangladesh. 2008. Super Cyclone Sidr 2007. Impacts and strategies for intervention; Ministry of Food and Disaster Management, Government of Bangladesh, Dhaka, Bangladesh.

Mahalder, B. K., F. Ahmed and S. Khan 2009. Salinity in the coastal region of Bangladesh: A curse to many and blessing to few. Paper presented at the International Seminar on Water Crisis in the Indian Subcontinent: Issues and Challenges, 23 - 25 November 2009, North Eastern Hill University, Shillong, India.

Practical Action - Bangladesh. 2007. A Study on People's Empowerment through Decentralized Knowledge Development and Management; Final Technical Report, Dhaka, Bangladesh, pp. 1-3.

Velden, van der M. 2002. The End of Diversity; Paper Presented at the Third International Conference on Cultural Attitudes Towards Technology and Communication, Canada.

Wikipedia. 2007. The free encyclopedia: http://en.wikipedia.org/wiki/Explicit Knowledge, 08 Jan, 2007;

World Bank. 2007. Floods in Bangladesh: Damage and Needs Assessment and Proposed Recovery Program; A Joint Report by The World Bank and The Asian Development Bank, Washington, D.C. 20433, USA, pp. 6-7.

World Bank. 2008. Cyclone Sidr in Bangladesh: Damage, loss and needs assessment for disaster recovery and reconstruction; A report prepared by the Government of Bangladesh Assisted by International Development Community. Washington, D.C. 20433, USA. pp. 3-4.

(Manuscript received on 5 March, 2017; revised on 10 April, 2017) 